\title{
The isolation of anaerobic bacteria from wound swabs
}

\author{
SUSAN PEACH AND L. HAYEK \\ From the Department of Bacteriology, St Mary's Hospital Medical School, London
}

SYNOPSIS The isolation of anaerobic bacteria from routine wound swabs by three procedures was evaluated.

Recovery of anaerobic organisms was doubled by immediate incubation of seeded plates, and $V_{\text {V }}$ the recovery could be further dramatically improved by the use of prereduced media, in conjunction ${ }^{\circ}$ with an anaerobic chamber.

Recommendations for the treatment of swabs and cultures for anaerobic investigation are made. $\stackrel{\circ}{?}$

As long ago as 1898, Veillon and Zuber noted that anaerobic fusiform bacilli were the commonest organisms associated with acute appendicitis but little attention was paid to these organisms, and since there was no reliable method of cultivating them, their significance in clinical infections was largely ignored.

With the advent of the modern anaerobic jar (McIntosh and Fildes, 1916; Brewer, 1939) and subsequent improvements (Khairat, 1964), more anaerobes have been recognized from clinical specimens. Using anaerobic jar systems, Stokes (1958) demonstrated the isolation of 496 anaerobes from 4737 positive cultures in her clinical laboratory over several years, and Gillespie and Guy (1956) isolated 117 strains of anaerobic bacteria from 111 clinical specimens.

Hungate (1950) studying oxygen-sensitive rumen bacteria devised a technique based on the production of oxygen-free culture media. Moore (1966) extended this method of production and the use of prereduced anaerobically sterilized media. McMinn and Crawford (1970) found prereduced media superior to routine laboratory methods for the isolation of anaerobes from clinical specimens.

Several workers have used prereduced media in anaerobic chambers for the study of normal flora (Spears and Freter, 1967; Drasar, 1967; Arank, Syed, Kenney, and Freter, 1969).

More recent work has concentrated on the conditions of transport of clinical specimens to the laboratory for anaerobic investigation (Attebery and Finegold, 1969). Specialized media for the isolation of anaerobes on the bench have also been devised Received for publication 17 April 1974. (eg, Watt, 1972).

In the present investigation, the isolation of anaerobes from routine wound swabs on simple solid media was examined by three methods in parallel: (1) the use of prereduced media in an anaerobic chamber; (2) anaerobic jar techniques specially performed; and (3) routine clinical laboratory techniques.

\section{Materials and Methods}

\section{SOURCE OF SWABS}

Swabs with plentiful material were selected from routine wound swabs sent for examination to the clinical laboratories of St Mary's Hospital. They had travelled from the wards by the hospital's usual collection and transport system.

\section{BACTERIOLOGICAL PROCEDURES}

\section{Bench procedures}

The swabs were seeded onto blood agar plates N (Oxoid Ltd, London, SE1) which had been stored N aerobically at $4^{\circ} \mathrm{C}$. In each case a seeded plate was immediately placed in a standard anaerobe jar (Baird \& Tatlock Ltd, Chadwell Heath, Essex), which was fitted with a palladium catalyst. The jar was evacuated, filled with hydrogen gas, and incu- $\mathbb{D}$ bated at $37^{\circ} \mathrm{C}$. Gas-Pak anaerobic indicator (Becton, Dickinson, UK Ltd, Wembley, Middlesex) was included in the jar. A second seeded plate was left on the bench until a suitable number of plates for incubation in an anaerobic jar had accumulated. This was the usual practice in the clinical laboratories of St Mary's Hospital. A palladium catalyst 
and Gas-Pak anaerobic indicator were included in the jar, which was evacuated, filled with hydrogen gas, and incubated at $37^{\circ} \mathrm{C}$. The plates were examined after 24 and 48 hours. A third plate was seeded and incubated aerobically at $37^{\circ} \mathrm{C}$.

\section{Cabinet procedures}

A flexible polyvinyl anaerobic chamber, similar to that described by Arank et al (1969), was employed. It was fitted with a stainless steel air lock and filled with a $90 \%$ nitrogen, $10 \%$ hydrogen gas mixture. The atmosphere was circulated by a fan over granules of palladium D catalyst (Engelhard Industries, Cinderford, Glos). The catalyst was changed weekly and was reactivated by heating at $180^{\circ} \mathrm{C}$ for one hour. A tray of silica gel was included in the chamber to absorb any moisture produced by the action of the catalyst.

Blood agar plates (Oxoid Ltd) were stored for three days in the chamber before use; the blood became darkened indicating reduction of the media. Swabs were introduced into the chamber via the air lock and were seeded onto the stored blood-agar plates. An electrically sterilized inoculating loop (Trotman and Drasar, 1968) was used to spread the inocula on the plates. The plates were placed in an anaerobe jar inside the chamber and the lid was screwed down. On removal from the chamber, the jar was evacuated and filled with a gas mixture containing $10 \% \mathrm{CO}_{2}$ and $90 \% \mathrm{H}_{2}$. Fresh palladium catalyst was included in all the jars. The plates were incubated at $37^{\circ} \mathrm{C}$ and examined on the bench after 24 and 48 hours.

\section{Isolation of anaerobes}

Colonies of suspected anaerobes were picked into Robertson's cooked meat medium (Southern Group Laboratories) and incubated at $37^{\circ} \mathrm{C}$ for three days. The cultures were examined for purity and for aerobic and anaerobic growth on blood-agar medium.

\section{Identification of anaerobes}

The isolates were assigned to genera on the basis of their appearance in a Gram-stained preparation (Preston and Morrell, 1962), and on the end products of glucose fermentation as detected by gasliquid chromatography. Species were assigned on the basis of biochemical tests (Holdeman and Moore, 1972). Inhibition of lecithinase by specific antitoxin on egg yolk medium was used as a confirmatory test for the detection of Clostridium welchii (Nagler, 1939).

\section{Gas-liquid chromatography}

A 4-ml portion of a three-day culture in $1 \%$ glucose broth (Holdeman and Moore, 1972) was acidified with $0.1 \mathrm{ml}$ of concentrated sulphuric acid (final pH $<2)$. The acidified cultures were placed in the water bath of a Perkin-Elmer F.40, multifract automatic gas chromatograph for head-space analysis. The temperature of the water-bath was $95^{\circ} \mathrm{C}$. The gas chromatograph was fitted with a flame-ionization detector and a $2 \mathrm{~m}$ stainless steel column packed with Diatomite $\mathrm{C}$ which had been treated with phosphoric acid and impregnated with $3 \%$ polyethylene glycol. The operating temperature was $125^{\circ} \mathrm{C}$ and the carrier gas was oxygen-free nitrogen passing through at $30 \mathrm{ml} / \mathrm{min}$.

\section{Results}

SELECTION OF SWABS FOR COMPARISON

Of 97 swabs cultured by the three different procedures, 21 of those processed in the anaerobic chamber, 24 of those examined on the bench with immediate incubation, and 26 of those incubated after delay yielded no bacterial growth. Within those three groups, overgrowth by spreading organisms made analysis of growth impossible in 12 , six, and four cases respectively. The number of swabs remaining for comparison in each group is shown in table I. All swabs that yielded anaerobes by one or more methods are included.

\begin{tabular}{|c|c|c|c|}
\hline & \multirow[t]{2}{*}{ Cabinet } & \multicolumn{2}{|l|}{ Bench } \\
\hline & & $\begin{array}{l}\text { Immediate } \\
\text { Incubation }\end{array}$ & $\begin{array}{l}\text { Delayed } \\
\text { Incubation }\end{array}$ \\
\hline $\begin{array}{l}\text { Total no. of swabs examined } \\
\text { No. recorded as no bacterial }\end{array}$ & 97 & 97 & 97 \\
\hline growth & 21 & 24 & 26 \\
\hline No. overgrown & 12 & 6 & 4 \\
\hline Total remaining & 64 & 67 & 67 \\
\hline No. of patients & 50 & 49 & 48 \\
\hline
\end{tabular}

Table I Selection of swabs for comparison

COMPARATIVE RECOVERY OF ANAEROBIC ORGANISMS

Anaerobes were isolated from $42.5 \%$ of the swabs processed in the anaerobic chamber, from $13.5 \%$ of those processed on the bench and immediately incubated, and from $4.5 \%$ of the swabs processed routinely (table II). For all the methods used, bacteroides organisms were the most common isolates. Anaerobic cocci and clostridia were also isolated (table III). The recovery rates for all anaerobic organisms, including the spore-forming clostridia, were improved by the use of the anaerobic chamber with prereduced media; the recovery of bacteroides was most noticeably improved. There was a less dramatic improvement with the rapid bench procedure. 


\begin{tabular}{lllc}
\hline & Cabinet & \multicolumn{2}{l}{ Bench } \\
\cline { 3 - 4 } & & $\begin{array}{l}\text { Immediate } \\
\text { Incubation }\end{array}$ & $\begin{array}{c}\text { Delayed } \\
\text { Incubation }\end{array}$ \\
\hline $\begin{array}{l}\text { Number of swabs } \\
\begin{array}{l}\text { Swabs (\%) yielding isolates of } \\
\text { anaerobes }\end{array}\end{array}$ & 64 & 67 & 67 \\
\hline
\end{tabular}

Table II Recovery of anaerobes from wound swabs

\begin{tabular}{llll}
\hline Organism & Cabinet & \multicolumn{2}{l}{ Bench } \\
\cline { 3 - 4 } & & $\begin{array}{l}\text { Immediate } \\
\text { Incubation }\end{array}$ & $\begin{array}{c}\text { Delayed } \\
\text { Incubation }\end{array}$ \\
\hline Bacteroides species & 22 & 5 & 2 \\
Anaerobic cocci & 7 & 3 & 1 \\
Clostridia & 5 & 1 & 1 \\
Total anaerobes & 34 & 9 & 4 \\
No. of patients from whom & 23 & 9 & 3 \\
anaerobes isolated & 23 & & 3 \\
\hline
\end{tabular}

Table III Numbers of isolates of various species

DISTRIBUTION OF ANAEROBES ISOLATED BY CABINET PROCEDURES

The 64 wound swabs that were processed in the anaerobic chamber included 33 swabs from abdominal and ischio-rectal sources, 13 of which yielded facultative organisms only and 20 of which yielded anaerobic organisms (table IV). In five cases only anaerobes were isolated. A single species of anaerobe was recovered in pure culture from three swabs and multiple species were isolated from two swabs. A single anaerobe and one or more facultative organisms were recovered from four others. Thirty-one wound swabs from other sites were also examined: these included burns, abscesses, and swabs from respiratory and renal operation wounds. Twenty-four of these yielded facultatives only. Anaerobes were isolated from only seven, which included two swabs from which a single anaerobe was isolated in pure culture. Single strains of anaerobic bacteria in mixed culture with facultative organisms were recovered from four swabs, and one swab yielded facultative organisms with two species of anaerobe.
NATURE OF ANAEROBIC ISOLATES
Of the organisms isolated in the anaerobic chamber, 은 $65 \%$ of isolates from abdominal swabs and $62.5 \%$ of $\overrightarrow{\vec{F}}$ isolates from other sources were bacteroides (table $\stackrel{?}{+}$ V). Fewer anaerobic cocci $(19 \%)$ were isolated from abdominal sources than from other sources $(25 \%)$. Fifteen per cent of the abdominal isolates were $\frac{\bar{\phi}}{\vec{\phi}}$

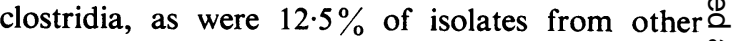
sources.

The majority of the bacteroides isolated were $\overrightarrow{0}$ identified as Bacteroides fragilis (table VI). Bac- teroides melaninogenicus was isolated twice, in both $\vec{\omega}$ instances from swabs of small bowel operations? wounds. The anaerobic cocci isolates were all Gram-positive organisms of the genera Peptococcus and ${ }^{2}$ Peptostreptococcus. The peptococci were Peptococcus $V$ asaccharotyticus and Peptococcus magnus. The anaerobic streptococci were identified as Pepto- $\infty$ streptococcus intermedius. The clostridia were all $\mathrm{O}$ Clostridium welchii.

\begin{tabular}{lll}
\hline & $\begin{array}{l}\text { Abdominal and } \\
\text { Rectal Source }\end{array}$ & $\begin{array}{l}\text { Other } \\
\text { Sources }\end{array}$ \\
\hline No. of swabs with anaerobes & 20 & 7 \\
No. of anaerobes isolated & 26 & 8 \\
\% Bacteroides & 65 & $62 \cdot 5$ \\
$\%$ Anaerobic cocci & 19 & 25 \\
$\%$ Clostridia & 15 & $12 \cdot 5$ \\
\hline
\end{tabular}

Table V Anaerobes isolated from wound swabs on prereduced media

\begin{tabular}{lc}
\hline Organism & No. of Isolates \\
\hline Bacteroides fragilis & 20 \\
Bacteroides melaninogenicus & 2 \\
Peptococcus asaccharolyticus & 2 \\
Peptococcus magnus & 2 \\
Peptostreptococcus intermedius & 2 \\
Clostridium welchii & 5 \\
Total & 34 \\
\hline
\end{tabular}

Table VI Identity of anaerobic isolates

\begin{tabular}{|c|c|c|c|c|c|c|c|}
\hline \multirow[t]{3}{*}{ Organism } & \multicolumn{7}{|c|}{ Type of Specimen (Source of Wound Swab) } \\
\hline & \multirow{2}{*}{$\begin{array}{l}\text { Total } \\
\text { Abdominal } \\
\text { and Rectal }\end{array}$} & \multicolumn{6}{|l|}{ Other } \\
\hline & & Total & Skin/Bone & $\begin{array}{l}\text { Superficial } \\
\text { Abscesses }\end{array}$ & Respiratory & Muscle & Renal \\
\hline Facultatives only & 13 & 24 & 10 & 7 & 4 & 2 & 1 \\
\hline Anaerobes & 20 & 7 & 4 & 1 & 1 & 一 & 1 \\
\hline Anaerobes only & 5 & 2 & 1 & 1 & - & - & - \\
\hline One species & 3 & 2 & 1 & 1 & - & - & 一 \\
\hline Two species & 2 & - & - & - & 一 & - & - \\
\hline Anaerobes and facultatives & 15 & 5 & 3 & - & 1 & - & 1 \\
\hline One species & 11 & 4 & 3 & - & - & - & 1 \\
\hline Two species & 4 & 1 & - & - & 1 & - & - \\
\hline
\end{tabular}

Table IV Distribution of anaerobes in 64 wound swabs ${ }^{1}$

${ }^{1}$ Figures represent actual numbers of specimens. 


\section{Discussion}

The clinical significance of anaerobes in wound infections cannot be assessed from the data obtained in this study. No patients were followed up and there was no assurance that the swabs were taken in a way that avoided contamination with normal flora. Indeed the high rate of recovery of anaerobes from abdominal and rectal sources might be accounted for by such contamination. This seems less likely in the seven cases where only anaerobes and no facultative organisms were recovered. It is interesting to note here that anaerobes were isolated more frequently together with facultative organisms than on their own. Macdonald, Gibbons, and Socransky (1960) and Moore and Gross (1968) have shown cases where anaerobic bacteria are pathogenic only where they exist in a synergistic situation with other bacteria.

The results of the present study indicate that immediate incubation of plates seeded on the bench is preferable to methods which involve delayed anaerobic incubation of seeded plates. No direct comparison can be made between the results obtained by cabinet and bench procedures since the $\mathrm{CO}_{2}$ content of the anaerobic jars differed in these two situations. However, the results of a similar study by Vargo, Michaelson, Spaudling, Vitagliano, Swanson, and Forsch (1971) in which $\mathrm{CO}_{2}$ was included in all anaerobic jars, were comparable with those obtained in this study (table VII). Lewis, Bedell, and Rettger (1940) and Watt (1973), working with pure cultures, have shown that adding $\mathrm{CO}_{2}$ increases both numbers and colony size of organisms incubated in anaerobic jars. The inclusion of $\mathrm{CO}_{2}$ in the gas mixture in anaerobic jars is to be recommended, although its effect on the recovery of anaerobes in the clinical situation may not be as dramatic as with pure cultures. Even with $\mathrm{CO}_{2}$ in the anaerobic jar, efficient isolation of anaerobes from routine clinical specimens can only be achieved with the use of prereduced media.
McMinn and Crawford (1972) found that prereduced liquid media were superior to solid media incubated in anaerobic jars for the isolation of anaerobes from clinical specimens known to contain anaerobes.

In contrast, Rosenblatt, Fallon, and Finegold (1973) showed that anaerobes could be isolated from clinical specimens just as effectively on the bench with anaerobic jar procedures as on prereduced solid media in an anaerobic chamber (table VII). However, in the latter study, the specimens were specially collected under anaerobic conditions, and speedily transported to the laboratory. Similarly, Dowell (1972), using prereduced solid media in an anaerobic chamber, found no improvement in the recovery of anaerobes from clinical specimens which had been submitted under anaerobic conditions.

In the present study the clinical specimens had been through the normal hospital transport system, and in many cases, several hours had elapsed between taking and cultivating the swabs. Throughout transportation the swabs were in an aerobic atmosphere. It is probable that many more organisms would have been recorded had the specimens been speedily submitted under anaerobic conditions, and it is hoped that, in future, efforts will be made to transport clinical specimens in anaerobic conditions.

It is encouraging that anaerobic organisms were isolated without employing specialized complicated media. Ordinary blood agar was used for all three procedures in this study.

Especially where it is not possible for specimens to be collected and transported anaerobically, methods are required for storing media in a reduced state and of keeping seeded plates in an anaerobic environment. To try to ensure that every culture for anaerobic incubation is put into an anaerobic jar immediately it is seeded would require extra technician time and a great many anaerobic jars. It is appreciated that many people feel that the anaerobic

\begin{tabular}{|c|c|c|c|c|c|c|c|c|c|}
\hline \multirow[t]{3}{*}{$\begin{array}{l}\text { No. of } \\
\text { Specimens }\end{array}$} & \multirow{2}{*}{\multicolumn{2}{|c|}{$\begin{array}{l}\text { McMinn and Crawford } \\
(1970) \\
38 \text { Specimens }\end{array}$}} & \multirow{2}{*}{\multicolumn{3}{|c|}{$\begin{array}{l}\text { Rosenblatt et al } \\
\text { (1973) } \\
23 \text { Specimens }\end{array}$}} & \multirow{2}{*}{\multicolumn{2}{|c|}{$\begin{array}{l}\begin{array}{l}\text { Vargo et al } \\
(1971)\end{array} \\
145 \text { Specimens }\end{array}$}} & \multirow{2}{*}{\multicolumn{2}{|c|}{$\begin{array}{l}\text { This Study } \\
64 \text { Specimens }\end{array}$}} \\
\hline & & & & & & & & & \\
\hline & Bench & $\begin{array}{l}\text { Prereduced } \\
\text { Anaerobically } \\
\text { Sterilized }\end{array}$ & Bench & Cabinet & $\begin{array}{l}\text { Prereduced } \\
\text { Anaerobically } \\
\text { Sterilized }\end{array}$ & Bench & Cabinet & Bench & Cabinet \\
\hline \multirow{3}{*}{$\begin{array}{l}\text { Anaerobic } \\
\quad \text { transportation } \\
+ \text { CO }^{*} \\
\% \text { Positive }\end{array}$} & & & & & & & & & \\
\hline & - & - & + & + & + & - & + & - & - \\
\hline & $\stackrel{+}{8.2}$ & $\stackrel{+}{100}$ & $\stackrel{+}{100}$ & $\stackrel{+}{100}$ & $\stackrel{+}{100}$ & $\underset{18}{+}$ & +4 & $\overline{13} \cdot 5$ & $\underset{42.5}{+}$ \\
\hline
\end{tabular}

Table VII Isolation of anaerobes from clinical specimens under various conditions 
chamber and air lock system, although a useful tool for research, is too cumbersome for the ordinary clinical laboratory. However, the increased rate of isolation of anaerobes should outweigh any disadvantages. Martin (1971) has described a cupboard and jar both capable of being flushed with oxygenfree gas, and this type of apparatus may also prove useful in the routine laboratory. Prereduced, anaerobically sterilized media are now being marketed commercially in the United States, and if this service is extended to Britain it would be a further possibility for routine use.

\section{References}

Arank, A., Syed, S. A., Kenney, E. B., and Freter, R. (1969). Isolation of anaerobic bacteria from human gingiva and mouse cecum by means of a simplified glove-box procedure. Appl. Microbiol., 17, 568-576.

Attebery, H. R., and Finegold, S. M. (1969). Combined screw-cap and rubber-stopper closure for Hungate tubes (pre-reduced anaerobically sterilized roll tubes and liquid media). Appl. Microbiol., 18, 558-561.

Brewer, J. H. (1939). A modification of the Brown anaerobe jar. J. lab. clin. Med., 24, 1190-1192.

Dowell, V. R., Jnr. (1972). Comparison of techniques for isolation and identification of anaerobic bacteria. Amer. J. clin. Nutr., 25, 1335-1343.

Drasar, B. S. (1967). Cultivation of anaerobic intestinal bacteria. J. Path. Bact., 94, 417-427.

Gillespie, W. A., and Guy, J. (1956). Bacteroides in intra abdominal sepsis. Lancet, 1, 1039-1042.

Holdeman, L., and Moore, W. E. C. (Eds.) (1972). The Anaerobe Laboratory Manual. Blacksburg, Virginia.

Hungate, R. E. (1950). The anaerobic mesophilic celluloytic bacteria. Bact. Rev., 14, 1-49.

Khairat, O. (1964). Modernizing Brewer and other anaerobic jars. J. Bact., 87, 963-964.

Lewis, K. H., Bedell, M., and Rettger, L. F. (1940). Non sporulating anaerobic bacteria of the intestinal tract. II. Growth facilitating factors. J. Bact., 40, 309-320.

Macdonald, J. B., Gibbons, R. J., and Socransky, S. S. (1960)으 Bacterial mechanisms in periodontal disease. Ann. N.Y. Acad." Sci., 85, 467-478.

McIntosh, J., and Fildes, P. (1916). A new apparatus for the isolation $\stackrel{\mathcal{O}}{+}$ and cultivation of anaerobic micro-organisms. Lancet, 1, 768-O 770.

McMinn, H. T., and Crawford, J. J. (1970). Recovery of anaerobic $\frac{\overline{\bar{O}}}{\overline{0}}$ micro-organisms from clinical specimens in pre-reduced media $\frac{\rho}{ᄀ}$ versus recovery by routine clinical laboratory methods. Appl. Microbiol., 19, 207-213.

Martin, W. J. (1971). Practical method for isolation of anaerobic bacteria in the clinical laboratory. Appl. Microbiol., 22, 11681171.

Moore, W. E. C. (1966). Techniques for the routine culture of fastidious anaerobes. Int. J. system. Bact., 16, 173-190.

Moore, W. E. C., and Gross, W. B. (1968). Liver granulomas of turkeys; causative agents and mechanism of infection. Avian Dis., 12, 417-422.

Nagler, F. P. O. (1939). Observations on a reaction between the lethal toxin of Clostridium welchii. (Type A) and human serum. Brit. J. exp. Path., 20, 473-485.

Preston, N. W., and Morrell, A. (1962). Reproducible results with the Gram stain. J. Path. Bact., 84, 241-243.

Rosenblatt, J. E., Fallon, A., and Finegold, S. M. (1973). Compari- $\infty$ son of methods for the isolation of anaerobic bacteria from 음 clinical specimens. Appl. Microbiol., 25, 77-85.

Spears, R., and Freter, R. (1967). Improved isolation of anaerobic bacteria from the mouse cecum by maintaining strict con- $\subseteq$ tinuous anaerobiosis. Proc. Soc. exp. Biol. (N.Y.), 124, 903-909.

Stokes, E. J. (1958). Anaerobes in routine diagnostic cultures. Lancet, $1,668-670$.

Trotman, R. E., and Drasar, B. S. (1968). Electrically heated inoculating loop. J. clin. Path., 21, 224-225.

Vargo, V., Michaelson, T. C., Spaudling, E. H., Vitagliano, R., Swanson, R. M., and Forsch, E. (1971). Comparison of pre-reduced anaerobic methods and Gas-Pak for isolating anaerobic bacteria. Bact. Proc., p. 109.

Veillon, A., and Zuber, A. (1898). Recherches sur quelques microbes strictment anaérobies et leur rôle en pathologie. Arch. Méd. d'éxp., 10, 517-545.

Watt, B. (1972). The recovery of clinically important anaerobes on solid media. J. med. Microbiol., 5, 211-218.

Watt, B. (1973). The influence of carbon-dioxide on the growth of 3 obligate and facultative anaerobes on solid media. J. méd. Microbiol., 6, 307-314. 